\title{
PERFORMANCE OF THE LAMPF OP'TICALLY PUMPED POLARIZED ION SOURCE
}

\author{
R.L. York, D. Tupa, D.R. Swenson, M.W. McNaughton, \\ and O.B. vanDyck \\ Los Alamos National Laboratory, Los Alamos, NM 87545
}

\begin{abstract}
In 1992, the LAMPF optically pumped polarized ion source (OPPIS) was used in experiments demanding a wide range of currents and polarizations. OPPIS was operated in different configurations to meet the differing current and polarization requirements for each experiment. We describe methods used to increase beam polarization at the expense of current for experiments that were count rate limited. OPPIS can be operated at $50 \mu \mathrm{A}$, giving $56 \%$ polarization, $25 \mu \mathrm{A}$ with $65 \%$ polarization, or $2 \mu \mathrm{A}$ with $77 \%$ polarization. The source reliability in 1992 was excellent, easily exceeding $95 \%$. Contributions to experimental systematic errors made by the source wcre measured in 1992. We speculate about further improvements that can be made to OPPIS.
\end{abstract}

A more complete description of OPPIS can be found elsewhere. I There are many factors that affect its performance. Some of these, such as the design of the ECR source. ECR extraction optics, or thickness of the alkali vapor in the ionizer cell, primarily affect the beam intensity. I. Others, such as the magnetic field at the polarizer cell or design of the Sona region, affect the $\mathrm{H}^{-}$beam polarization, $\mathrm{P}$. There arc many variables, however, that affect $I$ and $P$ simultaneously - usually in such a way that there is a tradeoff between the two. Understanding the variabless and how to compromise between I and $P$ has allowed us to meet the needs of different experimenters during the I.AMPI: 1992 run cycle.

One way of trading $P$ for $I$ is hy varying the thickness of the $p($ )larized $\mathrm{K}$ valpor target. The $\mathrm{H}^{-}$beam intensity increases linearly with $\mathrm{K}$ vapor thickness over a wide range of target thickenesscs. However, the vapor thickness that can be pumped to maximum polarization is restricted by the limited laser power and radiation trapping. 'This relationship has been reported by miny. 1,2,3,4

Another factor that determine: the relationship between $I$ and $P$ is the geconetry of the extraction optics of the EC' $R$ source. The plasma lens hass a hexagenal close-packed arraly of $1.0 \mathrm{~mm}$ dianceter holes with $0.25 \mathrm{~mm}$ spacing hetween holes. The $\mathrm{H}^{t}$ current extricted from the 
ECR (like the final $\mathrm{H}^{-}$beam) is proportional to the total extraction area and therefore the number of holes in the array; arrays of 7,19 , and 37 holes were used in 1992. The array size determines the diameter of the $\mathrm{H}^{+}$beam in the $\mathrm{K}$ cell. The $\mathrm{K}$ is more highly polarized along the axis of the polarizer cell because of depolarizing wall collisions at the walls and a higher laser intensity on the axis. Thus, the polarization is higher when more $\mathrm{H}^{0}$ beam is formed near the axis of the cell.

The range of $I$ and $P$ is also affected by aperturing the beam in the $750 \mathrm{kV}$ transport line. This result indicates a spatial dependence in the beam polarization. With a smaller aperture, current is lost, but the polarization is increased.

Figure 1 demonstrates how different source operating parameters can produce different values of $I$ and $P$. Data taken with three different $\mathrm{H}^{+}$heam diameters show how $\mathrm{P}$ is increased at the cost of 1 . For each extraction geometry, the thickness of the $K$ in the polarizer cell can be varied to give a range of source performance. The figure also shows how the polarization can be increased by inserting a small aperture at $750 \mathrm{kV}$.

In 1992, we examined contributions that OPPIS might make to systematic errors in precise experiments. 5 These measurements, descibed in the next two paragraphs, were made while the source was in normal operation with the 19-hole ECR extraction array and with no aperture in the $750 \mathrm{kV}$ beam line.

Systematic errors will result if the position, polarization, or current of the beam fluctuates in a way correlated to its spin state. We

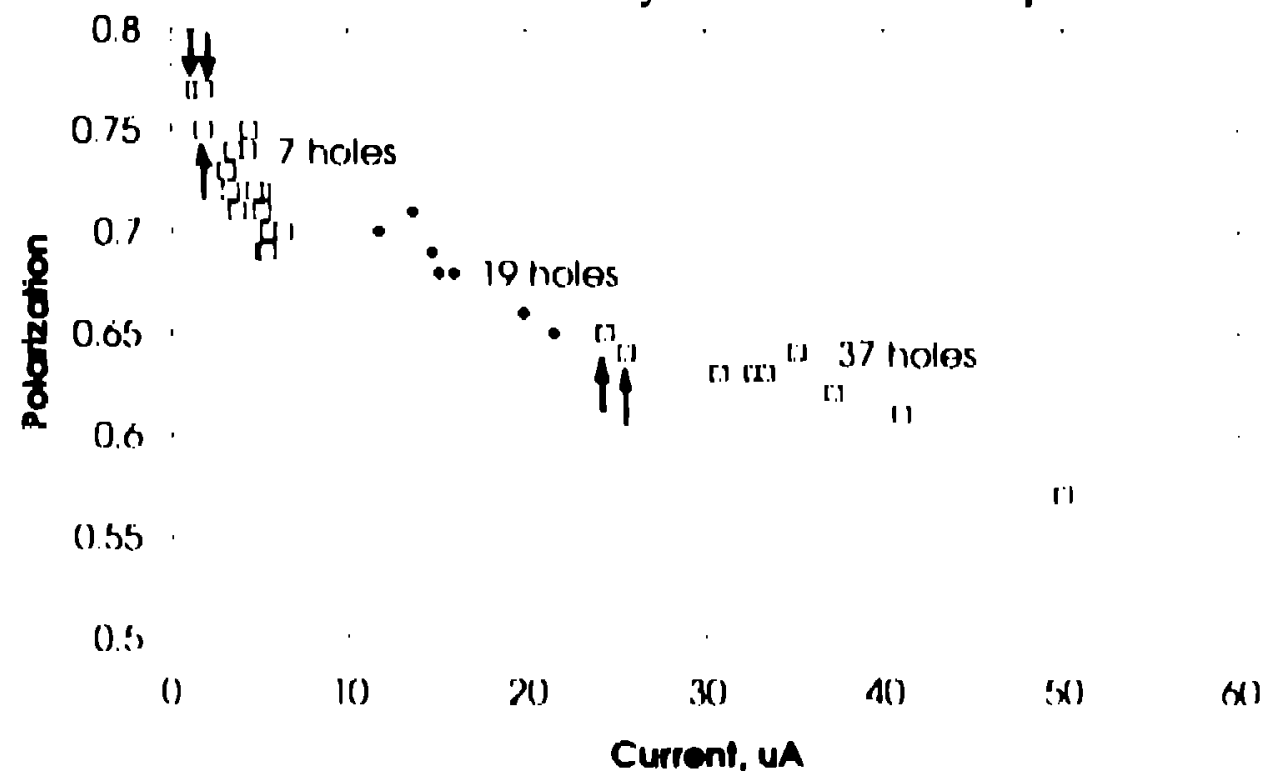

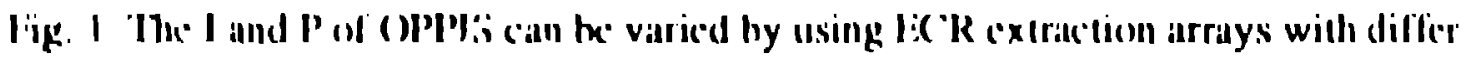
ent numbers of holess, as shown hy the diflerent symbols. 'The different datte points in vach series ane from placing an uperture in the $7.50 \mathrm{kV}$ beam line (denched with arows) or from changing llec thickness of the $\mathrm{K}$ vapur 

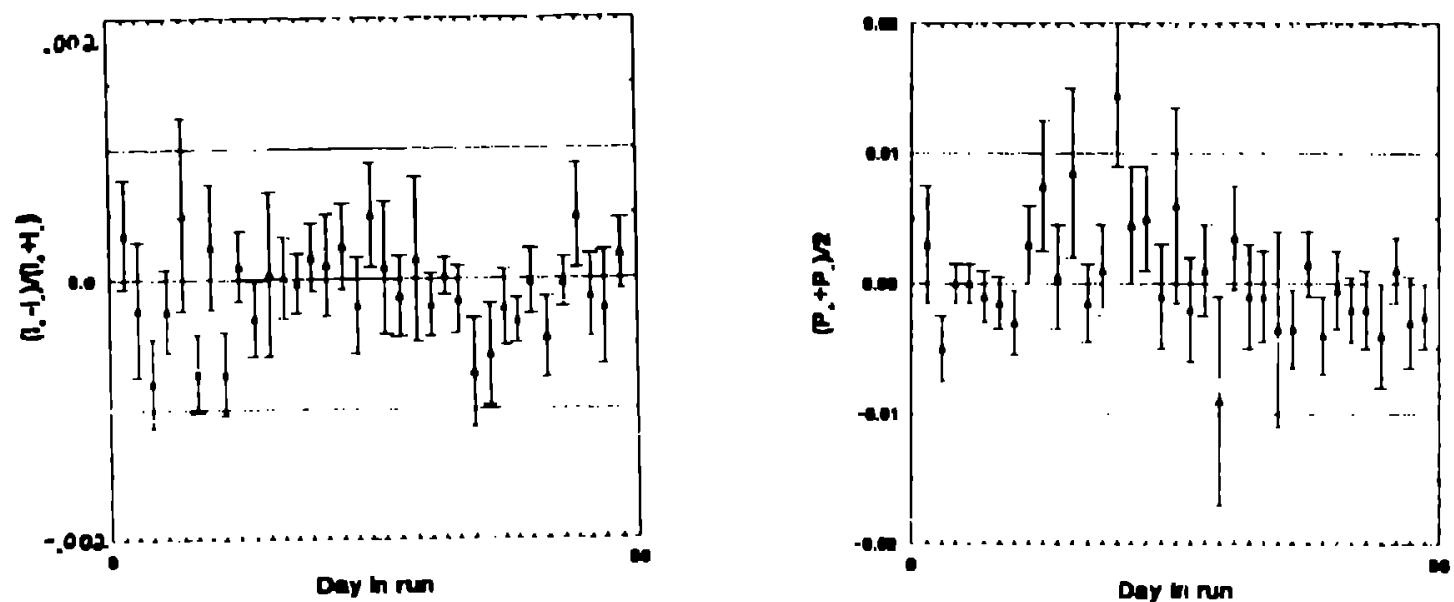

Fig. 2 (a) Intensity asymmetry $i$ and (b) polarization asymmetry $p$ vs. time. The time interval was from June 15 to July 25, 1992, during normal OPPIS beam production. In some cases. data from several days have heen combined, when the theam was off for a long time.

measured the motion of the $5 \mathrm{~mm}$ diameter beam to be $0+1-0.01 \mathrm{~mm}$. The asymmetry in the intensity, $i=\left(I_{+}-I_{-}\right) /\left(I_{+}-I_{-}\right)$, averaged $(-12+1-5) \times 10^{-5}$ over a month long period. The asymmetry in the polarization, $p=\left(P_{+}-P_{-}\right) / 2$, averaged $(-5+/-5) \times 10^{-4}$. Figure 2 shows $i$ and $p$ measured daily over a month.

There are other characteristics of the source that an experimenter may $t_{6}$ :ed to know in order to avoid systematic errors. Depending upon the lirac tune, the center of the full energy $800 \mathrm{MeV}$ beam had relative polarizations of up to $3 \%$ higher than the outer edge. The beam pulses are produced at $120 \mathrm{~Hz}$, each about $850 \mu \mathrm{s}$ long. Under some conditions, the relative polarization at the beginning of the pulse was up to $2 \%$ higher than at the end.

Table I outlines the performance of OPPIS since 1989. There are still some modifications that should be explored to improve the perfornance of OPPIS. Measurements made at TRIUMF6 confirm calculations 7 showing that higher polarizations are obtained if the magnetic field at the poliarizer cell is increased. Well over $10 \%$ relative improvement in polarization with no loss in current can be expected if a malgnet of higher field is installed. Studies show that the $\mathrm{H}^{+}$heam intensity from the $1: C \mathrm{C}$ is still limited by the amount of available ri power. The overall source performance is limited by the laser power available, and dalta indicate thit the $K$ vaper is less polarized near the walls than in the center of the larget. Therefore, more laser power would improve the current and polarization of the source.

In conclusion, (OPPIS has proven to be a source of remarkable versaltility. 'The range of its current and polarization can be balanced (o) accommodalte a wide range of centinds from experiments. OPISI relia- 
bility was well over $95 \%$ in 1992 . The eptically pumped source is well suited for high precision experiments, such as charge symmetry breaking or parity violation. There are many avenues that promise even better performance for OPPIS.

\begin{tabular}{|c|c|c|c|}
\hline & Current & Polarization & $\mathbf{P}^{2} \mathbf{I}$ \\
\hline Lamb-Shift Source & $0.8 \mu \mathrm{A}$ & $75 \%$ & $(0.45 \mu \mathrm{A}$ \\
\hline 1989 OPPIS & $4.0 \mu \mathrm{A}$ & $45 \%$ & $0.81 \mu \mathrm{A}$ \\
\hline I99(I OPPIS & $\begin{array}{l}25 \mu \mathrm{A} \\
15 \mu \mathrm{A}\end{array}$ & $\begin{array}{l}55 \% \\
62 \%\end{array}$ & $\begin{array}{l}7.6 \mu \mathrm{A} \\
5.8 \mu \mathrm{A}\end{array}$ \\
\hline 1991 OPPIS & $\begin{array}{l}38 \mu A \\
20 \mu A\end{array}$ & $\begin{array}{l}61) \% \\
64 \%\end{array}$ & $\begin{array}{l}14 \mu \mathrm{A} \\
8.2 \mu \mathrm{A}\end{array}$ \\
\hline 1992 (OPPI:; & $\begin{array}{l}5(1) \mu A \\
25 \mu A \\
2 \mu A\end{array}$ & $\begin{array}{l}56 \% \\
65 \% \\
77 \%\end{array}$ & $\begin{array}{l}16 \mu \mathrm{A} \\
11 \mu \mathrm{A} \\
1.2 \mu \mathrm{A}\end{array}$ \\
\hline
\end{tabular}

\section{REFERENCES}

I. R.L. York et al., in Prosecdings of the International Workshop on Polarized Ion Sources and Polarized Gas Jets. KEK-90-15, 170 (1990).

2. Y. Mori et al., "Report on optical pumping of sodium vapor with a pulsed dye laser." Kl:K Report 86-2 (1986).

3. L. Buchmann et al., in Proceedjngs of che International Workshop on Polarized Ion Sources and Polarized Gas Jets. KFK-P()-15, 161 $(1990)$, also ref. 6.

4. A.N. Telenski el al.. in Proceedings of the Internationill Workshop on Polarized lon Sources and Polirizeu Gas Jels. KIEK-9()-15, 1.54 $(190)$

5. D. Tupa et al., "Systematic errors in an optically pumped polarized ion source," accepted for publication in Nucl. Instrum. Methods.

6. (.I).P. levy et al." "Optimization studies of proson polarization in the TRIUMI: optically-pumped polarized ion source," accepted for publicition in Nucl. Instrum. Methods.

7. Fi. H. Hinds et al., Nucl Instrum Methods 189. 599 (1981). 